462 ANTIMALARIALS IMPROVE SURVIVAL OF SYSTEMIC
LUPUS ERYTHEMATOSUS ON CHOLESTEROL: RESULTS
OF A FIFTEEN-YEAR CHINESE MULTICENTER
RETROSPECTIVE STUDY IN JIANGSU PROVINCE

${ }^{1} \mathrm{~F}$ Wang ${ }^{*},{ }^{1} \mathrm{~W}$ Zhang, ${ }^{1} \mathrm{~S}$ Wang, ${ }^{2} \mathrm{~W}$ Pan, ${ }^{3} \mathrm{~L} \mathrm{Liu},{ }^{4} \mathrm{M}$ Wu, ${ }^{5} \mathrm{X}$ Ding, ${ }^{6} \mathrm{H}$ Wei, ${ }^{7} \mathrm{Y}$ Zou, ${ }^{1} X$ Feng, ${ }^{1} \mathrm{~L}$ Sun. ${ }^{1}$ Affiliated Drum Tower Hospital of Medical School - Nanjing University, Department of Rheumatology and Immunology, Nanjing, China; ${ }^{2}$ Huaian First People's Hospital, Department of Rheumatology-, Huaian, China; 'Xuzhou Central Hospital, Department of Rheumatology, Xuzhou, China; ${ }^{4}$ Third Affiliated Hospital of Soochow University, Department of Rheumatology, Changzhou, China; ${ }^{5}$ Lianyungang First People's Hospital, Department of Rheumatology, Lianyungang, China; ${ }^{6}$ Subei People's Hospital of Jiangsu province, Department of Rheumatology, Yangzhou, China; ${ }^{7}$ Wuxi People's Hospital, Department of Rheumatology, Wuxi, China

\subsection{6/lupus-2017-000215.462}

Background and aims Nowadays the importance of antimalarials, especially hydroxychloroquine (HCQ) and chloroquine (CQ), in treatment of systemic lupus erythematosus (SLE) has been demonstrated. However, few have examined the efficacy of HCQ and CQ on eastern Chinese SLE patients.

Methods The analysis is based on 1372 patients who were enrolled in a retrospective study of 26 centres from January $1^{\text {st }}, 1999$ through December $31^{\text {st }}, 2009$, during which time is their first hospitalisation. Baseline and follow-up clinical, laboratory and therapeutic data and survival status before April $30^{\text {th }}, 2015$ were recorded. Statistical analysis consist of Chisquare test, $t$-test, Kaplan-Meier curves and logrank test.

Results Compared with 562 patients without HCQ or CQ treatment, the hazard ratio (HR) of deaths in 810 patients taking those was reduced (HR 0.52, 95\% CI 0.38-0.70, $\mathrm{p}<0.001) .376$ of these 1372 patients experienced their second hospitalisation, during which treating group (165 of 376) showed high blood level of total cholesterol (TG), compared to control group $(4.47(0.13)$ vs $5.03(0.21), \mathrm{p}=0.027)$, while no statistical difference of TG exists between the two groups' first hospitalisation $(\mathrm{p}>0.05)$. Other metabolic data, such as systolic and diastolic blood pressure, fasting blood sugar, triglyceride and uric acid were similar between the two groups in two times of hospitalisation. On second inpatient visit, disease activity (SLE disease activity index, blood sedimentation rate, complement) and organ involvements of antimalarials takers and no users showed no significant differences either. Conclusions Use of HCQ or CQ lower the risk of mortality and TG levels of eastern Chinese SLE patients.

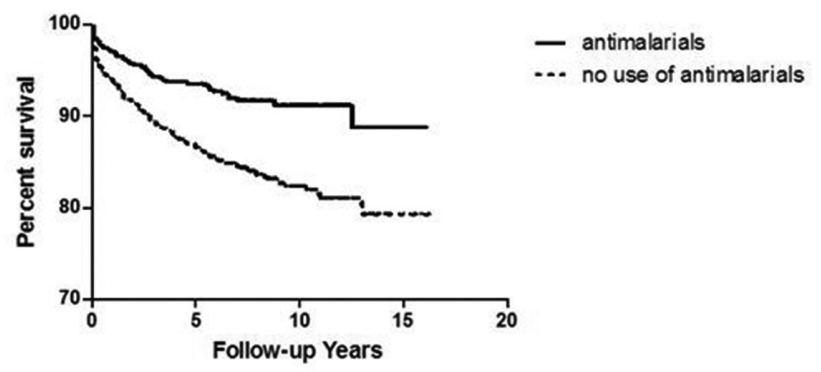

Abstract 462 Figure 1

\section{3 \\ STANDARDISED MORTALITY RATIO, OUTCOME AND PROGNOSTIC FACTORS OF NEUROPSYCHIATRIC SYSTEMIC LUPUS ERYTHEMATOSUS: A REAL WORLD SINGLE CENTRE STUDY}

${ }^{1} \mathrm{X}$ Li*, ${ }^{2} \mathrm{~S}$ Liu, ${ }^{3} Y \mathrm{Liu},{ }^{4} \mathrm{~L}$ Feng, ${ }^{1} \mathrm{C}$ Li, ${ }^{\prime} \mathrm{Z}$ Li. ${ }^{1}$ Peking University People's Hospital, Department of Rheumatology and Immunology, Beijing, China; ${ }^{2}$ Peking University, Third Hospital, Beijing, China; ${ }^{3}$ Jilin University Fourth Hospital, Department of Geriatrics, Changchun, China; ${ }^{4}$ No.2 Hospital Xiamen, Department of Rheumatology and Immunology, Xiamen, China

\subsection{6/lupus-2017-000215.463}

Background and aims To investigate the survival rate and prognostic factors of neuropsychiatric systemic lupus erythematosus (NPSLE) in a cohort.

Methods A total of 101 NPSLE inpatients diagnosed in a single centre from 2005 to 2016 were included. Information on survival status, date and causes of death was acquired by follow-up. Data were analysed using Kaplan-Meier curves, logrank tests and Cox proportional hazards modelling.

Results The overall survival rates of the NPSLE cohort were $89 \%, 85 \%$ and $84 \%$ at 1,3 and 5 years respectively. The standardised mortality ratio (SMR) of NPSLE patients was 11.14. The most common cause of death was NPSLE (7, $47 \%)$, including intracranial hypertension syndrome (4, 27\%), cerebrovascular disease $(2,13 \%)$ and motor neuron disease (1, $7 \%)$. The remaining causes included other SLE complications (3, 20\%) and infection (2, 13\%). Crude analysis showed that the following variables at diagnosis were associated with a shorter survival period: cardiac involvement, renal involvement, diffuse NPSLE, acute confusional state, number of NPSLE manifestations $>1$, lymphocyte $<10^{9} /$ L, elevated Creactive protein(CRP), abnormal cerebrospinal fluid and high systemic lupus erythematosus disease activity index (SLEDAI). On multivariate analysis, acute confusional state $(\mathrm{p}=0.004)$, high SLEDAI $(p=0.020)$ and elevated CRP $(p=0.023)$ were independently prognostic of death.

Conclusions Our study demonstrate an 11.14-fold increased mortality of NPSLE patients compared with general population. NPSLE itself is the most frequent cause of death. Acute confusional state is the most significant predictive factor for poor prognosis.

\section{LUPUS LOW DISEASE ACTIVITY STATE: PREVALENCE AND EFFECT ON DAMAGE ACCRUAL IN A MONOCENTRIC COHORT OF 293 SLE PATIENTS}

A Doria*, M Zen, F Saccon, M Gatto, M Larosa, L laccarino. University of Padova, Department of Medicine DIMED-Division of Rheumatology, Padova, Italy

\subsection{6/lupus-2017-000215.464}

Background and aims To assess the prevalence and validate the effect on damage accrual of the recently defined "Lupus Low Disease Activity State"(LLDAS) in a monocentric cohort of patients with Systemic Lupus Erythematosus (SLE).

Methods We studied 293 Caucasian SLE patients during 7 year follow-up. Disease activity was assessed by SLEDAI-2K and SELENA-SLEDAI physician global assessment (PGA), and damage by SLICC/ACR Damage Index (SDI). Franklyn et $\mathrm{al}^{1}$ 
Abstract 464 Table 1 Demographics and prevelance of LLDAS and damage in the study cohort.

\begin{tabular}{|l|c|c|c|c|c|c|c|c|}
\hline & $\begin{array}{c}\text { Total study } \\
\text { cohort } \\
293\end{array}$ & $\begin{array}{c}\text { Never in } \\
\text { LLDAS } \\
39(13.3)\end{array}$ & $\begin{array}{c}\text { 1-year } \\
\text { LLDAS } \\
35(11.9)\end{array}$ & $\begin{array}{c}\text { 2-year } \\
\text { LLDAS } \\
51(17.4)\end{array}$ & $\begin{array}{c}3 \cdot \text { year } \\
\text { LLDAS } \\
50(17.0)\end{array}$ & $\begin{array}{c}\text { 4-year } \\
\text { LLDAS } \\
29(9.9)\end{array}$ & $\begin{array}{c}\geq 5 \cdot \text { year } \\
\text { LLDAS } \\
89(30.5)\end{array}$ & $P$ \\
\hline $\begin{array}{l}\text { Age in 2009, yeass, } \\
\text { mean } \pm \text { SD }\end{array}$ & $39.1 \pm 12.5$ & $39.9 \pm 13$ & $36.6 \pm 16.4$ & $40.0 \pm 13.0$ & $42.4 \pm 11.7$ & $41.9 \pm 11.2$ & $39.8 \pm 12.5$ & ns. \\
\hline Female, No (\%) & $253(86.3)$ & $32(82.1 \%)$ & $29(82.9)$ & $47(92.2)$ & $41(82)$ & $23(79.3)$ & $81(91.0)$ & ns. \\
\hline $\begin{array}{l}\text { SLE duration a 2015, } \\
\text { years, mean } \pm \text { SD }\end{array}$ & $17.2 \pm 7.8$ & $17.2 \pm 7.9$ & $16.6 \pm 7.0$ & $19.1 \pm 8.3$ & $18.6 \pm 8.0$ & $17.0 \pm 7.9$ & $18.1 \pm 7.2$ & ns. \\
\hline $\begin{array}{l}\text { SDI at baseline, } \\
\text { mean } \pm S D\end{array}$ & $0.64 \pm 1.04$ & $0.87 \pm 1.17$ & $0.94 \pm 1.53$ & $0.90 \pm 1.08$ & $0.62 \pm 0.91$ & $0.48 \pm 0.78$ & $0.34 \pm 0.74$ & $<0.05 *$ \\
\hline MeantSD SDI increase & $0.77 \pm 0.95$ & $1.57 \pm 1.35$ & $1.20 \pm 0.90$ & $0.88 \pm 0.89$ & $0.85 \pm 0.87$ & $0.45 \pm 0.69$ & $0.27 \pm 0.49$ & $<0.001$ \\
\hline $\begin{array}{l}\text { Increase in SDI, No. } \\
\text { patients (\%) }\end{array}$ & $151(51.5)$ & $31(79.5)$ & $28(80)$ & $31(60.8)$ & $28(56)$ & $11(37.9)$ & $22(24.7)$ & $<0.001$ \\
\hline
\end{tabular}

SD, standard deviation; SDI, SLICC/ACR damage index

$P$ values refer to ANOVA test with 5 degrees of freedom.

* 1-year LLDAS us 25-year LLDAS, $p=0.004$; 2-year LLDAS vs 25 -year LLDAS, $p=0.018$, for other comparison, $p=n$ s.

definition of LLDAS was applied: (1) SLEDAI-2K $\leq 4$, with no activity in major organ systems (renal, central nervous system, cardiopulmonary, vasculitis, fever) and no haemolytic anaemia or gastrointestinal activity; (2) no new lupus activity compared with the previous assessment; (3) a PGA (scale 0-3) $\leq 1$; (4) current prednisolone-equivalent dose $\leq 7.5 \mathrm{mg} /$ day; (5) stable maintenance dose of immunosuppressants.

The effect of different durations of LLDAS $(1,2,3,4, \geq 5$ consecutive years) on SDI was evaluated by multivariate logistic regression analysis.

Results The prevalence of LLDAS and damage in the cohort are reported in Table 1.

Patients who spent at least 2 consecutive years in LLDAS had significantly reduced damage accrual compared with patients never in LLDAS $(\mathrm{p}=0.001)$. Interestingly, among the 254 patients achieving LLDAS for at least 1 year, 231 (90.9\%) had clinical-SLEDAI-2K=0. At multivariate analysis, a LLDAS lasting at least two years was protective against damage (Table 2). Conversely, major independent predictors of damage were cumulative prednisone dose $\geq 180 \mathrm{mg} / \mathrm{month}$ and antiphospholipid antibody syndrome (Table 2).

Conclusions Two consecutive years was the shortest LLDAS duration associated with a decrease in damage progression in Caucasian SLE patients.

\section{REFERENCE}

1. Franklyn K, et al. Ann Rheum Dis 2016;75:1615-1621.

\section{Vaccines, adjuvants and autoimmunity}

\section{SULFASALAZINE-RELATED HYPERSENSITIVITY REACTIONS IN PATIENTS WITH RHEUMATIC DISEASES}

T Senturk*, S Cildag. Adnan Menderes University - Medical Faculty, Rheumatology, Aydin, Turkey

\subsection{6/lupus-2017-000215.465}

Background and aims Sulfonamide related allergic drug reactions are common, and their rate is reported to be $3.0 \%$ for the general population. Sulfasalazine (SSZ), which is an inflammatory drug in the arylamine sulfonamide structure, is being used for the treatment of many rheumatic diseases. In this study, we aimed to determine the frequency of sulfasalazine-related hypersensitivity reactions in patients with rheumatic disease.

Methods A total of 136 patients (84 RA and 52 AS) were included in this study. Patients were screened for those who recently started using sulfasalazine treatment. The type of the reaction, duration of the reaction, administered medicines, and their doses were recorded in patients with detected hypersensitivity during the follow-up. The drug was stopped and antihistaminic and/or corticosteroid treatment was administered as needed. In patients with a negative prick test, a drug provocation test (DPT) was performed after drugs were stopped and amino salicylic acid.

Results A total of 136 patients, with ages ranging from 19 to 71 (mean 41.97 \pm 12.04 ), were included in the study. 